Kálmán, Anikó

\title{
THE MEANING AND IMPORTANCE OF THOMAS KUHN'S CONCEPT OF 'PARADIGM SHIFT'. HOW DOES IT APPLY IN EDUCATION?
}

\section{Introduction}

In order to understand the meaning and importance of Thomas Kuhn's concept of 'paradigm shift', I started with an extensive bibliographical and web research, from which I compiled what I thought to be the most relevant points.

"In The Structure of Scientific Revolutions Kuhn asserts that there are important shifts in the meanings of key terms as a consequence of a scientific revolution" (Bird, 2004).

\section{Thomas Kuhn}

"Of the five books and countless articles Thomas Kuhn published, his most renowned work is The Structure of Scientific Revolutions" (Wade, 2004).

Throughout thirteen succinct but thought-provoking chapters, Kuhn argued that science is not a steady, cumulative acquisition of knowledge, but "a series of peaceful interludes punctuated by intellectually violent revolutions" [Nicholas Wade, writing for Science], which he described as "the tradition-shattering complements to the tradition-bound activity of normal science." After such revolutions, "one conceptual world view is replaced by another" [Wade].

Although critics chided him for his imprecise use of the expression, Kuhn was responsible for popularizing the term paradigm, which he described as essentially a collection of beliefs shared by scientists, a set of agreements about how problems are to be understood. According to Kuhn, paradigms are essential to scientific inquiry, for "no natural history can be interpreted in the absence of at least some implicit body of intertwined theoretical and methodological belief that permits selection, evaluation, and criticism." Indeed, a paradigm guides the research efforts of scientific communities, and it is this criterion that most clearly identifies a field as a science. A fundamental theme of Kuhn's argument is that the typical developmental pattern of a mature science is the successive transition from one paradigm to another through a process of revolution. When a paradigm shift takes place, "a scientist's world is qualitatively transformed [and] quantitatively enriched by fundamental novelties of either fact or theory."

Kuhn argued that a scientific revolution is a non-cumulative developmental episode in which an older paradigm is replaced in whole or in part by an incompatible new one. But the new paradigm cannot build on the preceding one. Rather, it can only supplant it, for "the normalscientific tradition that emerges from a scientific revolution is not only incompatible but actually incommensurable with that which has gone before." Revolutions conclude with total victory for one of the two opposing camps.

Kuhn also took issue with Karl Popper's view of theory-testing through falsification. According to Kuhn, it is the incompleteness and imperfection of the existing data-theory fit that define the puzzles that characterize normal science. If, as Popper suggested, failure to fit were grounds for theory rejection, all theories would be rejected at all times. 
As to whether progress consists in science discovering ultimate truths, Kuhn observed that "we may have to relinquish the notion, explicit or implicit, that changes of paradigm carry scientists and those who learn from them closer and closer to the truth." Instead, the developmental process of science is one of evolution from primitive beginnings through successive stages that are characterized by an increasingly detailed and refined understanding of nature. Kuhn argued that this is not a process of evolution toward anything, and he questioned whether it really helps to imagine that there is one, full, objective, true account of nature. He likened his conception of the evolution of scientific ideas to Darwin's conception of the evolution of organisms.

The Kuhnian argument that a scientific community is defined by its allegiance to a single paradigm has especially resonated throughout the multiparadigmatic (or preparadigmatic) social sciences, the members of whose communities are often accused of paradigmatic physics envy. Kuhn suggested that questions about whether a discipline is or is not a science can be answered only when members of a scholarly community who doubt their status achieve consensus about their past and present accomplishments.

As Frank Pajares (2004a) writes, "a scientific community cannot practice its trade without some set of received beliefs. These beliefs form the foundation of the "educational initiation that prepares and licenses the student for professional practice." The nature of the "rigorous and rigid" preparation helps ensure that the received beliefs are firmly fixed in the student's mind. Scientists take great pains to defend the assumption that scientists know what the world is like. To this end, "normal science" will often suppress novelties which undermine its foundations. Research is therefore not about discovering the unknown, but rather "a strenuous and devoted attempt to force nature into the conceptual boxes supplied by professional education."

A shift in professional commitment to shared assumptions takes place when an anomaly undermines the basic tenets of the current scientific practice. These shifts are what Kuhn describes as scientific revolutions - "the tradition-shattering complements to the traditionbound activity of normal science." New assumptions -"paradigms" - require the reconstruction of prior assumptions and the re-evaluation of prior facts. This is difficult and time consuming. It is also strongly resisted by the established community.

So how are paradigms created, and what do they contribute to scientific inquiry?

Normal science "means research firmly based upon one or more past scientific achievements, achievements that some particular scientific community acknowledges for a time as supplying the foundation for its further practice." These achievements must be sufficiently unprecedented to attract an enduring group of adherents away from competing modes of scientific activity and sufficiently open-ended to leave all sorts of problems for the redefined group of practitioners (and their students) to resolve. These achievements can be called paradigms. Students study these paradigms in order to become members of the particular scientific community in which they will later practice.

James Franklin (2000) claims that the basic content of Kuhn's book can be inferred simply by asking: what would the humanities crowd want said about science? Once the question is asked, the answer is obvious. Kuhn's thesis is that scientific theories are no better than those found in the humanities. The idea that science is all theoretical talk and negotiation, which never really establishes anything, is one that caused trouble long ago for Galileo, who wrote: 
If what we are discussing were a point of law or of the humanities, in which neither true nor false exists, one might trust in subtlety of mind and readiness of tongue and in the greater experience of the writers, and expect him who excelled in those things to make his reasoning more plausible, and one might judge it to be the best.

Kuhn's "achievement" was to put the view of Galileo's scholastic opponents back on the agenda. Up to his time, philosophy of science had concentrated on such questions as how evidence confirms theories and what the difference is between science and pseudo-science; that is, questions about the logic of science. Kuhn declared logic outmoded and replaced it with history.

At a more logical level, Kuhn's success depended on certain ambiguities. Even in the caricature above, it is clear how some were essential to Kuhn's plan. What does "unsustainable" mean when said of a scientific theory? In particular, is it a matter of logic or of psychology? If it means that there are a number of observed results that would be unlikely if the theory were true, then one is back in the realm of logic, of the bad old philosophy of science that studied the relation of evidence to hypothesis. Naturally, Kuhn is not keen to emphasize that direction. But if "unsustainable" is a purely psychological matter, a kind of collective disgust felt by a salon des refusés of younger scientists who simply think their elders are too smug, then it is impossible to see why it should have any standing as science. If the old theory ain't broke-if its predictions are true, for example, and its explanations coherent-why fix it?

It is clear why Fuller's argument is a similar version when he says "We can know things only via causal (social) processes acting on the brains of real scientists, therefore the content of our theories is fully explained by the social factors causing them; that is, we cannot know things as they are in themselves. Scientists are people, after all, and as such are responsive only to social or similar causes."

\section{What is a Paradigm?}

Imran Javaid (1997) looks specifically at the question: What is a Paradigm? At the core of Kuhn's thoughts is the notion of "paradigms." While Kuhn cannot claim exclusive credit for coining the word, no intellectual work popularized the word as his Structure did. Though one source claims that Kuhn utilizes twenty-one implicit meanings for the word during the course of his long essay, Kuhn offers an initial definition that readers can easily hold on to as legitimate. Paradigms are essentially scientific theories or ways of looking at the world that fulfil two requirements: they must be "sufficiently unprecedented to attract an enduring group of adherents away from competing modes of scientific activity," and they must be "sufficiently open-ended to leave all sorts of problems for the redefined group of practitioners to resolve."

Indeed, even in this initial definition, readers can already detect, through words such as "adherents," the manner in which Kuhn often presents his arguments. While his ideas may not be totally revolutionary in and of themselves, his language often portrays paradigms as cults and the battle between paradigms as quasi-religious wars.

The breakdown of old paradigms and emergence of new ones is often assisted by social forces. For evidence, Kuhn looks briefly at the sixteenth century debate over Copernicus' ideas. 
One important aspect of Kuhn's philosophy involves the idea that "the decision to reject one paradigm is always simultaneously the decision to accept another, and the judgment leading to that decision involves the comparison of both paradigms with nature and with each other." Why is this the case? Kuhn points partly to social reasons: "To reject one paradigm without simultaneously substituting another is to reject science itself."

In The Development of Science Bird (2000) tells us that "in The Structure of Scientific Revolutions Kuhn paints a picture of the development of science quite unlike any that had gone before. Indeed, before Kuhn, there was little by way of a carefully considered, theoretically explained account of scientific change. Instead, there was a conception of how science ought to develop that was a by-product of the prevailing philosophy of science, as well as a popular, heroic view of scientific progress."

According to Kuhn the development of a science is not uniform but has alternating "normal" and "revolutionary" (or "extraordinary") phases.

This conservative resistance to the attempted refutation of key theories means that revolutions are not sought for except under extreme circumstances. Popper's philosophy requires that a single reproducible, anomalous phenomenon be enough to result in the rejection of a theory (Popper 1959, 86-7). Kuhn's view is that during normal science scientists neither test nor seek to confirm the guiding theories of their disciplinary matrix. Nor do they regard anomalous results as falsifying those theories. It is only speculative puzzle-solutions that can be falsified in a Popperian fashion during normal science (1970b, 19). Rather, anomalies are ignored or explained away if at all possible. It is only the accumulation of particularly troublesome anomalies that poses a serious problem for the existing disciplinary matrix.

The most interesting response to crisis will be the search for a revised disciplinary matrix, a revision that will allow for the elimination of at least the most pressing anomalies and optimally the solution of many outstanding and unsolved puzzles. Such a revision will be a scientific revolution. According to Popper the revolutionary overthrow of a theory is one that is logically required by an anomaly. According to Kuhn however, there are no rules for deciding on the significance of a puzzle and for weighing puzzles and their solutions against one another. The decision to opt for a revision of a disciplinary matrix is not one that is rationally compelled; nor is the particular choice of revision rationally compelled. For this reason the revolutionary phase is particularly open to competition among differing ideas and to rational disagreement about their relative merits. Kuhn does briefly mention that extrascientific factors might help decide the outcome of a scientific revolution - the nationalities and personalities of leading protagonists, for example (1962/1970a, 152-3). This suggestion grew in the hands of some sociologists and historians of science into the thesis that the outcome of a scientific revolution, indeed of any step in the development of science, is always determined by socio-political factors. Kuhn himself repudiated such ideas and his work makes it clear that the factors determining the outcome of a scientific dispute, particularly in modern science, are almost always to be found within science, specifically in connexion with the puzzle-solving power of the competing ideas. 


\section{According to Bird (2004) the Paradigm Concept is that}

... a mature science, according to Kuhn, experiences alternating phases of normal science and revolutions. In normal science the key theories, instruments, values and metaphysical assumptions that comprise the disciplinary matrix are kept fixed, permitting the cumulative generation of puzzle-solutions, whereas in a scientific revolution the disciplinary matrix undergoes revision, in order to permit the solution of the more serious anomalous puzzles that disturbed the preceding period of normal science.

Kuhn rejected the distinction between the context of discovery and the context of justification (1962/1970a, 8), and correspondingly rejected the standard account of each. As regards the context of discovery, the standard view held that the philosophy of science had nothing to say on the issue of the functioning of the creative imagination. But Kuhn's paradigms do provide a partial explanation, since training with exemplars enables scientists to see new puzzle-situations in terms of familiar puzzles and thus enables them to see potential solutions to their new puzzles.

More important for Kuhn was the way his account of the context of justification diverged from the standard picture. The functioning of exemplars is intended explicitly to contrast with the operation of rules. The key determinant in the acceptability of a proposed puzzlesolution is its similarity to the paradigmatic puzzle-solutions. Perception of similarity cannot be reduced to rules, and a fortiori cannot be reduced to rules of rationality. This rejection of rules of rationality was one of the factors that led Kuhn's critics to accuse him of irrationalism. In this respect at least the accusation is wide of the mark: it is perfectly reasonable to claim that perceiving similarity in appearance between two members of the same family cannot be reduced to the application of rules of rationality. Kuhn's innovation in The Structure of Scientific Revolutions was to suggest that "a key element in cognition in science operates in the same fashion."

\section{Shifts in the meanings of key terms}

"In The Structure of Scientific Revolutions Kuhn asserts that there are important shifts in the meanings of key terms as a consequence of a scientific revolution (Bird, A., 2004).

Kuhn's view as expressed in the passage quoted above depends upon meaning holism - the claim that the meanings of terms are interrelated in such a way that changing the meaning of one term results in changes in the meanings of related terms. Another not unrelated source is the assumption of holism in the philosophy of science that is consequent upon the positivist conception of theoretical meaning. According to the latter, it is not the function of the theoretical part of scientific language to refer to and describe unobserved entities. Only observational sentences directly describe the world, and this explains why they have the meaning that they do. Theories permit the deduction of observational sentences. This is what gives theoretical expressions their meaning. Theoretical statements cannot, however, be reduced to observational ones. This is because, first, theoretical propositions are involved collectively in the deduction of observational statements, rather than singly. Consequently, the meaning of a theoretical sentence is not equivalent to the meaning of any observational sentence or combination of observational sentences. The meaning of a theoretical term is a product of two factors: the relationship of the theory or theories of which it is a part to its 
observational consequences and the role that particular term plays within those theories. This is the double-language model of the language of science and was the standard picture of the relationship of a scientific theory to the world when Kuhn wrote The Structure of Scientific Revolutions. Kuhn's challenge to it lay not in rejecting the anti-realism implicit in the view that theories do not refer to the world but rather in undermining the assumption that the relationship between observation and the world is unproblematic.

Although Kuhn asserted a semantic incommensurability thesis in The Structure of Scientific Revolutions he did not articulate or argue for the thesis in detail there. He attempted to do this in his subsequent work, with the result that the nature of the thesis changed over time. At the heart of the incommensurability thesis after The Structure of Scientific Revolutions is the idea that certain kinds of translation are impossible. Early on Kuhn drew a parallel with Quine's thesis of the indeterminacy of translation (1970a, 202; 1970c, 268). According to the latter, if we are translating one language into another, there are inevitably a multitude of ways of providing a translation that are adequate to the behaviour of the speakers. None of the translations is the correct one, and in Quine's view there is no such thing as the meaning of the words to be translated. It was nonetheless clear that Quine's thesis was rather far from Kuhn's thesis, indeed that they are incompatible. First, Kuhn thought that incommensurability was a matter of there being no fully adequate translation whereas Quine's thesis involved the availability of multiple translations. Secondly, Kuhn does believe that the translated expressions do have a meaning, whereas Quine denies this. Thirdly, Kuhn later went on to say that unlike Quine he does not think that reference is inscrutable-it is just very difficult to recover $(1976,191)$.

The problematic nature of translation arises from two assumptions. First, as we have seen, Kuhn assumes that meaning is (locally) holistic. A change in the meaning of one part of the lexical structure will result in a change to all its parts. This would rule out preservation of the translatability of taxonomies by redefining the changed part in terms of the unchanged part. Secondly, Kuhn adopts the 'no-overlap' principle which states that either categories in a taxonomy must be disjoint or one must be a subset of the other. They cannot simply overlap. This rules out the possibility of an all-encompassing taxonomy that incorporates both the original and the changed taxonomies.

\section{Conclusions}

Kuhn's influence outside professional philosophy of science may have been even greater than it was within it. The social sciences in particular took up Kuhn with enthusiasm. There are two main reasons for this. First, Kuhn's picture of science appeared to permit a more liberal conception of what science is than hitherto: one that could be taken to include disciplines such as sociology and psychoanalysis. Secondly, Kuhn's rejection of rules as determining scientific outcomes appeared to permit appeal to other factors, external to science, in explaining why a scientific revolution took the course that it did.

However, the incommensurability thesis is not Kuhn's only positive philosophical thesis. Kuhn himself tells us that "the paradigm as shared example is the central element of what I now take to be the most novel and least understood aspect of this book" (1970a, 187). Nonetheless, he failed to develop the paradigm concept in his later work beyond an early application of its semantic aspects to the explanation of incommensurability. The explanation of scientific development in terms of paradigms was not only novel but radical 
too, insofar as it gives a naturalistic explanation of belief-change. Naturalism was not in the early 1960s the familiar part of the philosophical landscape that it has subsequently become. Kuhn's explanation contrasted with explanations in terms of rules of method (or confirmation, falsification etc.) that most philosophers of science took to be constitutive of rationality. Furthermore, the relevant disciplines (psychology, cognitive science, artificial intelligence) were either insufficiently advanced to support Kuhn's contentions concerning paradigms, or were antithetical to them (in the case of classical Al). Now that naturalism has become an accepted component of philosophy, there has recently been interest in reassessing Kuhn's work in the light of developments in the relevant sciences, many of which provide corroboration for Kuhn's claim that science is driven by relations of perceived similarity and analogy to existing problems and their solutions (Nickles 2003b, Nersessian 2003). It may yet be that a characteristically Kuhnian thesis will play a prominent part in our understanding of science.

"The first edition of Thomas Kuhn's The Structure of Scientific Revolutions appeared just over 30 years ago, in 1962. His vision has revolutionized the way we think about science, and has given us as well a new way to look at change in all of life." (Healy, 1992).

A vision of science that preceded Kuhn saw science as an accumulation of all that had been learned over history, each new law adding its weight to the mass of knowledge. Kuhn saw something else. He saw a science profoundly altered by a major new law, so that all of that science might be affected. Kuhn envisioned a science as having, at any one time, a world view, or "paradigm", of its environment. This scientific paradigm describes everything that the science holds, all of its laws, beliefs, procedures and methods, everything upon which it bases its life. Kuhn felt that most scientists participate in "normal science", which is any activity consistent with the existing paradigm, with relatively small gains as the rule. Eventually, anomalies arise which the paradigm cannot resolve. Then some individual(s) may step out of the paradigm, and propose some new principle or law. If the scientific community accepts the proposed change, the science experiences a "paradigm shift", and the new science proceeds with a new paradigm. (Benedek and Molnár 2013, Molnár 2010, Szúts 2012)

Whether in the sciences, or in other aspects of our lives, paradigm shifts seem to have some common characteristics.

Paradigm shifts are a necessary part of life. Things do change, and we have to adjust to that change.

Paradigm shifts can be bad. Society needs quite a bit of stability, so that it can depend on its view of the world. Constant shifts in major elements of our paradigm would make our lives very difficult.

Paradigm shifts often come from the young. Older people have more to conserve. They have more invested, financially and psychologically, in their paradigm. Winston Churchill is reported to have said that any man who is not a liberal at 20 has no heart, and any man who is not a conservative at 40 has no mind.

You cannot abandon a paradigm until you have one to put in its place, because our paradigm is that which allows us to function. Without a paradigm, good or bad, we cannot function.

It usually takes a long time to effect a paradigm shift - often as much as 20 years, about the life of a generation. (See above, and for an example, see also Hunt, 1991) 
As Malcolm Gladwell wrote in The New Yorker, "That [Kuhn's] idea was intended to apply only to the natural sciences did not matter. It was so novel, so persuasive, and - upon the monograph's publication as a book, in 1970 - so perfectly in the rebellious spirit of the times that it quickly became adopted as a kind of general theory of everything."

Kuhn's ideas were indeed truly pervasive. In philosophy, history, sociology, economics, politics, and even religion, Kuhn's theory of paradigms changed the nature of the fields.

Perhaps Gladwell summed up Kuhn's legacy best when he wrote "Kuhn will be remembered because he taught that the process of science was fundamentally human, that discoveries were the product not of some plodding, rational process but of human ingenuity intermingled with politics and personality--that science was, in the end, a social process."

\section{Bibliography}

Books by Thomas Kuhn

- 1957, The Copernican Revolution: Planetary Astronomy in the Development of Western Thought, Cambridge Mass: Harvard University Press.

- 1962/1970a, The Structure of Scientific Revolutions, Chicago: University of Chicago Press (1970, 2nd edition, with postscript).

- 1977a, The Essential Tension. Selected Studies in Scientific Tradition and Change, Chicago: University of Chicago Press.

- 1978, Black-Body Theory and the Quantum Discontinuity, Oxford: Clarendon Press (2nd edition, Chicago: University of Chicago Press).

- 2000, The Road Since Structure, edited by James Conant and John Haugeland, Chicago: University of Chicago Press.

Selected papers of Thomas Kuhn

- 1959, "The Essential Tension: Tradition and Innovation in Scientific Research", in The Third (1959) University of Utah Research Conference on the Identification of Scientific Talent edited by C. Taylor, Salt Lake City: University of Utah Press: 162-74.

- 1963, "The Function of Dogma in Scientific Research", in Scientific Change, edited by A. Crombie (London: Heinemann: 347-69).

- 1970b, "Logic of Discovery or Psychology of Research?", in Criticism and the Growth of Knowledge, edited by I. Lakatos and A. Musgrave, London: Cambridge University Press: 1-23.

- 1970c, "Reflections on my Critics", in Criticism and the Growth of Knowledge, edited by I. Lakatos and A. Musgrave, London: Cambridge University Press: 231-78.

- 1974, "Second Thoughts on Paradigms", in The Structure of Scientific Theories, edited by F. Suppe, Urbana: University of Illinois Press: 459-82.

- 1976, "Theory-Change as Structure-Change: Comments on the Sneed Formalism", Erkenntnis 10: 179-199.

- 1977b, "The Relations between the History and the Philosophy of Science", in his The Essential Tension, Chicago: University of Chicago Press: 3-20.

- 1977c, "Objectivity, Value Judgment, and Theory Choice", in his The Essential Tension, Chicago: University of Chicago Press: 320-39. 
- 1979, "Metaphor in Science", in Metaphor and Thought, edited by A. Ortony Cambridge: Cambridge University Press: 409-19.

- 1980, "The Halt and the Blind: Philosophy and History of Science", (review of Howson Method and Appraisal in the Physical Sciences, Cambridge: Cambridge University Press) British Journal for the Philosophy of Science 31: 181-92.

- 1983a, "Commensurability, Comparability, Communicability", PSA 198: Proceedings of the 1982 Biennial Meeting of the Philosophy of Science Association, edited by P. Asquith. and T. Nickles, East Lansing: Philosophy of Science Association: 669-88.

- 1983b, "Rationality and Theory Choice", Journal of Philosophy 80: 563-70.

- 1987, "What are Scientific Revolutions?", in The Probabilistic Revolution edited by L. Krüger, L. Daston, and M. Heidelberger, Cambridge: Cambridge University Press: 722.

- 1990, "Dubbing and Redubbing: The Vulnerability of Rigid Designation", in Scientific Theories edited by C. Savage, Minnesota Studies in Philosophy of Science 14, Minneapolis, University of Minnesota Press: 298-318.

- 1991a, "The Road Since Structure", PSA 1990. Proceedings of the 1990 Biennial Meeting of the Philosophy of Science Association vol.2, edited by A. Fine, M. Forbes, and L. Wessels., East Lansing: Philosophy of Science Association: 3-13.

- 1991b, "The Natural and the Human Sciences", in The Interpretative Turn: Philosophy, Science, Culture, edited by D. Hiley, J. Bohman, and R. Shusterman, Ithaca: Cornell University Press: 17-24.

- 1992, "The Trouble with the Historical Philosophy of Science", Robert and Maurine Rothschild Distinguished Lecture, 19 November 1991, An Occasional Publication of the Department of the History of Science, Cambridge Mass: Harvard University Press.

- 1993, "Afterwords" in World Changes. Thomas Kuhn and the Nature of Science, edited by P. Horwich, Cambridge Mass: MIT Press: 311-41.

Other references and literature

- Andersen, H., 2001, On Kuhn, Belmont CA: Wadsworth.

- Bakos, F., 1997, Idegen szavak és kifejezések kéziszótára [Dictionary of foreign words and expressions], Akadémiai Kiadó: Budapest

- Barnes, B., 1982, T.S.Kuhn and Social Science, London: Macmillan.

- Bird, A., 2000, Thomas Kuhn, Chesham: Acumen and Princeton, NJ: Princeton University Press.

- Bird, A., 2004, Thomas Kuhn, The Stanford Encyclopedia of Philosophy (Fall 2004 Edition), Edward N. Zalta (ed.), <http://plato.stanford.edu/archives/fall2004/entries/thomas-kuhn/>. http://plato.stanford.edu/entries/thomas-kuhn/

- Bird, A., 2005, "Naturalizing Kuhn ", Proceedings of the Aristotelian Society 105: 109127.

- Bruner, J. and Postman, L., 1949, "On the Perception of Incongruity: A Paradigm", Journal of Personality 18: 206-23.

- Clark, D., 2004, Leadership, http://nwlink.com/ donclark/documents/leadershipshareware.html

- Cohen, I.B., 1985, Revolution in Science, Cambridge MA: Harvard University Press. 
- Devitt, M., 1979, "Against Incommensurability", Australasian Journal of Philosophy 57: 29-50.

- Doppelt, G., 1978, “Kuhn's Epistemological Relativism: An Interpretation and Defense", Inquiry 21: 33-86;

- Enç, B. 1970, "Reference and Theoretical Terms", Noûs 10: 261-282.

- ETF (European Training Foundation), 1998, Development of Core Skills Training in The Partner Countries, Subgroup D, Final Report (prepared by Simon Shaw, with contributions on EU countries from Pekka Kamarainen)

- Evans, G. 1973 "The Causal Theory of Names", Proceedings of the Aristotelian Society, Suppl. vol. 47: 187-208.

- Evers, F. T., Rush, J. C., Berdrow, I., 2001, The Bases of Competence: Skills for Lifelong Learning and Employability, John Wiley \& Sons, http://www.wiley.com/Corporate/Website/Objects/Products/0,9049,104995,00.html

- Franklin, J., 2000, Thomas Kuhn's irrationalism, http://www.newcriterion.com/archive/18/jun00/kuhn.htm

- Fuller, S. 2000, Thomas Kuhn: A Philosophical History for our Times, Chicago: University of Chicago Press.

- Gutting, G., 1980, Paradigms and Revolutions, Notre Dame: University of Notre Dame Press.

- Hacking, I. (ed.), 1981, Scientific Revolutions, Oxford: Oxford University Press.

- Healy, T., 1992, Thomas Kuhn, Santa Clara University http://www.ee.scu.edu/eefac/healy/kuhn.html

- Hanson, N. R., 1958, Patterns of Discovery, Cambridge: Cambridge University Press.

- Horwich, P. (ed.), 1993, World Changes. Thomas Kuhn and the Nature of Science, Cambridge, Mass.: MIT Press.

- Hoyningen-Huene, P., 1989, Die Wissenschaftsphilosophie Thomas S. Kuhns: Rekonstruktion und Grundlagenprobleme, translated as Hoyningen-Huene, P., 1993, Reconstructing Scientific Revolutions: Thomas S. Kuhn's Philosophy of Science, Chicago: University of Chicago Press.

- Hunt, B.J., 1991, The Maxwellians, Cornell University Press, Ithica, NY.

- Javaid, I., 1997, Thomas Kuhn: Paradigms Die Hard, Harvard Science Review,http://www.people.fas.harvard.edu/ nagiel/99_hsr_webpage/hsr/winter97/ kuhn.html

- Kálmán, A., 2014, Paradigm Shift in Higher Education Collaboration: Cooperation Instead of Competition. In: EDEN 2014 Annual Conference: E-learning at work and the workplace. Zagreb, Croatia, 2014.06.10-2014.06.13. Paper E3/177_Kalman. 4 p.

- Kálmán, A., 2012, Training of Trainers. Paradigm Shift in Qualitative Higher Education. In: IACEE 2012 World Conference on Continuing Engineering Education, 17-19 May 2012, Valencia, Spain, ISBN: 978-84-8363-858-3 (CD)

- Katona, J., Ujbanyi, T., Kovari, A., 2015 Investigation of the Correspondence between Problems Solving Based on Cognitive Psychology Tests and Programming Course Results, International Journal of Emerging Technologies in Learning, Vol. 10, No 3, 62-65.

- Kripke, S., 1980, Naming and Necessity, Cambridge MA: Harvard University Press.

- Kroon, F. 1985, "Theoretical Terms and the Causal View of Reference", Australasian Journal of Philosophy 63: 143-166. 
- Lakatos, I., Musgrave, A. (eds.), 1970, Criticism and the Growth of Knowledge, London: Cambridge University Press.

- Longino, H., 1994, "In Search of Feminist Epistemology", Monist 77: 472-485.

- Martin, E., 1991, "The Egg and the Sperm: How science has constructed a romance based on stereotypical male-female sex roles", in E. Keller and H. Longino, eds., 1996, Feminism and Science, Oxford: Oxford Univ. Press.

- Molnár, György and András Benedek 2013, "ICT Related Tasks and Challenges In The New Model of Technical Teacher Training", In John Terzakis, Constantin Paleologu, Tibor Gyires (eds.) 2013: The Eighth International Multi-Conference on Computing in the Global Information Technology. Nice: InfoWare 40-44.

- Molnár, György 2010, "The Dimensions of Permanent Learning in the Light of Sustainable Development", In Kálmán Anikó (ed.) Lifelong Learning, Innovation and the Creation of Values / MELLearN 6th Hungarian National and International Lifelong Learning Conference Proceedings 2010. 202-210.

- Musgrave, A., 1971, "Kuhn's Second Thoughts", British Journal of the Philosophy of Science 22: 287-97.

- Nagel, E. 1961, The Structure of Science, London: Routledge and Kegan Paul.

- Nelson, L. H., 1993, “Epistemological Communities”, In L. Alcoff and E. Potter, (eds.) 1993, Feminist Epistemologies, New York: Routledge.

- Nersessian, N., 2003, "Kuhn, Conceptual Change, and Cognitive Science" in (Nickles 2003a) 178-211.

- Newton-Smith, W., 1981, The Rationality of Science, London: Routledge.

- Nickles, T., 2003a, Thomas Kuhn, Cambridge: University of Cambridge Press.

- Nickles, T., 2003b, "Normal Science: From Logic to Case-Based and Model-Based Reasoning", in Nickles 2003a, 142-177.

- Nola, R., 1908, "Fixing the Reference of Theoretical Terms", Philosophy of Science 47: 505-531.

- Pajares, F., 2004, Outline and Study Guide on The Structure of Scientific Revolutions of Thomas S. Kuhn, Emory University, http://www.emory.edu/EDUCATION/mfp/Kuhn.html

- Pajares, F., (2004a), "The Structure of Scientific Revolutions by Thomas S. Kuhn - A Synopsis from the original", Philosopher's Web Magazine, http://www.emory.edu/EDUCATION/mfp/kuhnsyn.html

- Pickering, A., 1984, Contructing Quarks: A Sociological History of Particle Physics Chicago; University of Chicago Press.

- Popper, K., 1959, The Logic of Scientific Discovery London: Hutchinson.

- Putnam, H., 1975a, Mind, Language, and Reality: Philosophical Papers Vol. 2, Cambridge: Cambridge University Press.

- Putnam, H., 1975b, "The Meaning of 'Meaning'” in (Putnam 1975a).

- Sankey, H., 1993, "Kuhn's Changing Concept of Incommensurability", British Journal of the Philosophy of Science 44: 759-74.

- Sankey, H., 1994, The Incommensurability Thesis, Aldershot: Avebury.

- Scheffler, I., 1967, Science and Subjectivity, Indianapolis: Bobbs-Merrill.

- Schiebinger, L., 1999, Has Feminism Changed Science?, Cambridge, MA: Harvard University Press. 
- Schoolnet, 2000, Employability Skills, Canada http://www.schoolnet.ca/EmployabilitySkills

- Shapere, D., 1964, "The Structure of Scientific Revolutions", Philosophical Review 73: 383-94.

- Sharrock, W. and Read, R., 2002, Kuhn: Philosopher of Scientific Revolution, Cambridge: Polity.

- Sherman, R., Weidler, D., Tibbetts, J., Dobbins, D., 2000 : Management Competencies and Sample Indicators for the Improvement of Adult Education programs, Building Professional Development Partnerships for Adult Educators Project, PRO - NET, Pelavin Research Institute, http://www.air-dc.org/nrs/default.htm

- Siegel, H., 1980 “Objectivity, Rationality, Incommensurability and More”, British Journal of the Philosophy of Science 31: 359-84.

- Szúts Z., 2012, "An Iconic Turn in Art History - The Quest for Realistic and 3D visual Representation on the World Wide Web", In András Benedek and Kristóf Nyíri, (eds.) 2012, The Iconic Turn in Education (Visual Learning), Frankfurt: Peter Lang Internationaler Verlag der Wissenschaften, 59-66.

- Toulmin, S., 1970 "Does the Distinction between Normal and Revolutionary Science Hold Water?", in Lakatos and Musgrave 1970, 39-5

- Wade, N., 2004, Thomas Kuhn, Emory University, Atlanta, Georgia, http://www.emory.edu/EDUCATION/mfp/Kuhnsnap.html. 